\title{
The Influence of Asset-Liability Ratio on Enterprise value -Empirical Analysis Based on Threshold Regression
}

\author{
Maoli $\mathrm{Ji}^{1,}$ a , Bo Huo ${ }^{1, \mathrm{~b},{ }^{*}}$ \\ ${ }^{1}$ College of Economics, Binhai Campus, Bohai Ununiversity, Jinzhou City, Liaoning Province, China \\ aemail, bhuohuo0416@163.com \\ ${ }^{*}$ Corresponding author
}

Keywords: Asset-liability ratio, The enterprise value, Threshold regression.

\begin{abstract}
In order to maximize enterprise value, effective financial management is needed. Therefore, it really matters to conduct a study of the relation between asset-liability ratio and enterprise value. This paper chooses the data of Guoted Companies in China from 2016 to 2018, do the studies of the correlation between asset-liability ratio and enterprise value with the threshold regression, and analyzes the debt-to-assets ratio that affects on enterprise value .Through empirical analysis, the asset-liability ratio of enterprises has a positive effect on the value of enterprises, but there is a threshold of asset-liability ratio. Therefore, the increase of the enterprise's asset-liability ratio can improve the value of the enterprise, but it can not increase the enterprise's debt-to-assets ratio indefinitely. Therefore, enterprises should borrow money rationally for the sake of maximizing the worth of enterprises.
\end{abstract}

\section{Introduction}

Under the condition of market economy, liability management is generally adopted by enterprises to maximize economic benefits and realize scale management. This is a significant condition for the continuous development of the firm. However, there should be a "degree" of liability. Moreover, excessive debt may make the enterprise into trouble, even bankruptcy. Because of its excessive debt management, the company named Liaoning xinglong big family business group has faced the financial management and management difficulties after the state's financial policy tightening of financial managements. This article wants to provide the reference for the enterprise is how to control the asset-liability ratio to achieve the desired enterprise value, through the analysis of enterprise relation of asset-liability ratio and enterprise value.

\section{Literature Review and Research Hypothesis}

\subsection{Literature Review}

At present, domestic scholars in China have abundant research results on the pertinence between asset-liability ratio and enterprise value, which can be roughly divided into three viewpoints. In the first view, the asset-liability ratio of enterprises is positively related to the the value of the company. For example, Ming liu, guoliang yuan (1999), yifeng shen, xixi hong (2000), kemin wang, changjiang lv (2002), hui wang (2003) and others proved the positive correlation from different perspectives. The second view is that the asset-liability ratio of enterprises is negative correlation with the corporate value, that is, the increasing financial leverage of the company will devalue the enterprise value. The research of linjiang wu, genfu feng, shiyan liu (2000), zuoping xiao (2005) also reached a consistent conclusion. The third point of view is that changjiang lv and huibo han (2007) established simultaneous equations with the asset composition balance panel data as the object of study, and the research showed that the impact of capital composition on the company's performance was nonlinear and there was an "inverted u-shaped" correlation.

In conclusion, due to the reasons of time, policy, region and industry, research results on the relation of asset-liability ratio and enterprise value are different. On account of the change of national policies in recent years, the influence of asset-liability ratio on enterprise value has also 
changed accordingly. As a consequence, it is very momentous to go into the reasonable liability range of enterprises.

\subsection{Research Hypothesis}

According to the theoretical research results of asset-liability ratio and enterprise value, this paper makes assumptions on the relation between asset-liability ratio and enterprise value:

Hypothesis 1: the asset-liability ratio of an enterprise has a positive impact on the enterprise value.

According to the analysis of hu yuancheng (2002), the optimal asset-liability ratio of the listed companies in China should be $60 \%$. Initial assumption of this paper:

Hypothesis 2: there is a threshold for the influence of asset liability ratio on enterprise value. There is an optimal level of debt-to-assets ratio. Before the level of the optimal asset-liability ratio, the enterprise value is positively correlated with the asset-liability ratio. When it exceeds the level of the optimal asset-liability ratio, the impact on the enterprise value is no longer significant.

\section{Research Design}

\subsection{Sample Selection and Data Sources}

This paper make a study of the impact of asset-liability ratio with enterprise value, and select public company data from 2016 to 2018 as samples. This paper selected 1,000 valid data samples from different types of companies with securities codes from 000001 to 000110 from the fourth quarter of 2016 to the second quarter of 2018. Considering the data availability and the robustness of the research results, this paper eliminated the companies lacking financial data. This paper uses the financial data of listed companies all from CSMAR database. Data processing adopts STATA15.0.

\subsection{Definition of variables}

\subsubsection{Explained Variable}

In this paper, enterprise value is taken as the explained variable, and tobin $\mathrm{Q}$ value commonly used by scholars inland and abroad is selected to measure, reflecting the degree of investors' recognition of the growth and development prospects of the company. When studying the relationship between enterprise value and other factors, tobin Q can more truly reflect the value of Chinese enterprises, with strong operability and simple calculation. With share structure reform and the continuous improvement of the capital market, this index can more truly measure the actual value of a company.

\subsubsection{Explanatory Variables}

In this paper, the debt-asset ratio (LEV) was used as the explanatory variable. The debt-asset ratio $=$ total liabilities/total assets $\times 100 \%$.

\subsubsection{Control Variables}

The control variables of this paper are earnings per share (EPS) and return on equity (ROE).

\subsubsection{Threshold Variable}

In this paper, the threshold variable is asset-liability ratio (LEV), which $=$ total liabilities/total assets $\times 100 \%$.

Table 1. Description of variables and Description of measurement.

\begin{tabular}{ccc}
\hline Variable Types & Variable Symbol & Description of Meaning and Measurement \\
\hline Explained Variable & TBQ & $\begin{array}{c}\text { Tobin's = Market Value of Assets/Book Value of Assets }= \\
\text { (Market Value of Equity + Market Value of Net } \\
\text { Debt)/Total Accounting Value of Assets at the end of the } \\
\text { period }\end{array}$ \\
\hline Explanatory Variables & LEV & Asset-Liability Ratio = Total Liabilities/Total Assets \\
\hline Control Variables & EPS & $\begin{array}{c}\text { Earnings Per Share }=\text { Net Profit Current Value/Paid-in } \\
\text { Capital Current Ending Value }\end{array}$ \\
& ROE & Return on quity = Net Profit/Average balance of equity \\
\hline Threshold variable & LEV & Asset-Liability Ratio = Total Liabilities/Total Assets \\
\hline
\end{tabular}




\subsection{Establishment of Threshold Regression Model}

In reality, the economic impact between variables is asymmetric and non-linear. Therefore, under different variable threshold conditions, the impact of different independent versus dependent is greatly different. In order to study the above nonlinear threshold effect, statisticians use the time series threshold regression method in the time series model to capture the threshold values of different threshold variables and estimate the corresponding regression coefficients of explanatory variables within different threshold values. In this time series model, the influence mechanism of time series model jumps before and after a particular time point. Therefore, from the perspective of measurement technology, data is usually divided into two periods before and after the time point, and then the regression of the data model is carried out respectively and the difference of regression coefficients is compared, and the model test is carried out according to different regression statistics. On this basis, econometricians completed relevant theoretical results of threshold model on the basis of time series model: threshold time series model (autoregressive model) and inertia-threshold autoregressive model. Then, Hansen constructed a fixed effect threshold regression model for panel data based on the non-linear and asymmetric relationship between threshold variables and response variables.

Based on Hansen's research results, this study constructed the following model:

$$
\mathrm{tbq}=\beta 1 \mathrm{roe}+\beta 2 \text { eps }+\beta 3 \operatorname{lev}(\operatorname{lev} \prec \gamma)+\beta 4 \operatorname{lev}(\operatorname{lev} \succ \gamma)+\varepsilon
$$

\section{Model Regression Results and Analysis}

Threshold estimator (level $=95)$ :

\begin{tabular}{c|ccc}
\hline model & Threshold & Lower & Upper \\
\hline Th-1 & 0.0980 & 0.0961 & 0.1093
\end{tabular}

Threshold effect test (bootstrap $=300)$ :

\begin{tabular}{c|ccccccc}
\hline Threshold & RSS & MSE & Fstat & Prob & Crit10 & Crit5 & Critl \\
\hline Single & $1.31 \mathrm{e}+04$ & 17.2256 & 17.61 & 0.2200 & 23.1313 & 31.5361 & 75.0775 \\
\hline
\end{tabular}

Fixed-effects (wxtzhin) regression

Group variable:region

$$
\begin{aligned}
\text { R-sq: } & \text { within }=0.0238 \\
\text { between } & =0.0566 \\
\text { overall } & =0.0355
\end{aligned}
$$

$$
\operatorname{corr}\left(u_{-} 1, \mathrm{Xb}\right)=0.0434
$$

$$
\begin{aligned}
& \text { Number of obs }=770 \\
& \text { Number of groups }=\quad 110 \\
& \text { Obs per group: } \min =\quad 7 \\
& \operatorname{avg}=\quad 7.0 \\
& \max =7 \\
& \mathrm{~F}(4,656)=4.00 \\
& \text { Prob }>\text { F }=0.0032
\end{aligned}
$$

\begin{tabular}{r|rcrrrr}
\hline tbq & Coef. & Std. Err. & $\mathrm{t}$ & $\mathrm{P}>|\mathrm{t}|$ & [95\% Conf. Interval] \\
\hline roe & -.0001982 & .002963 & -0.07 & 0.941 & -.0054863 & .0050898 \\
eps & -.1598673 & .564188 & -0.28 & 0.777 & -1.267699 & .9479649 \\
_cat\#c.lev & & & & & & \\
0 & 56.06593 & 14.24288 & 3.94 & 0.000 & 28.09879 & 84.03306 \\
1 & 2.203338 & .890476 & 2.47 & 0.014 & .4548114 & 3.951865 \\
& & & & & \\
cons & .9642516 & .4689099 & 2.06 & 0.040 & .0435062 & 1.884997 \\
\hline sigma_u & 3.2194501 & & & & \\
sigma_e & 4.4760801 & \multicolumn{7}{c}{ (fraction of variance due to u i) } \\
rho & .3409476 & & & &
\end{tabular}

$\mathrm{F}$ test that all $\mathrm{u} \mathrm{i}=0: \mathrm{F}(109,656)=3.60 \quad$ Prob $>\mathrm{F}=0.0000$ 


\begin{tabular}{|c|c|}
\hline VARIABLES & $\begin{array}{l}\text { (1) } \\
\text { tbq }\end{array}$ \\
\hline roe & $\begin{array}{c}-0.000198 \\
(0.00269)\end{array}$ \\
\hline eps & $\begin{array}{l}-0.160 \\
(0.564)\end{array}$ \\
\hline 0b._cat\#c.lev & $\begin{array}{c}56.07 * * * \\
(14.24)\end{array}$ \\
\hline 1._cat\#c.lev & $\begin{array}{c}2.203 * * \\
(0.890)\end{array}$ \\
\hline Constant & $\begin{array}{c}0.964 * * \\
(0.469)\end{array}$ \\
\hline Observations & 770 \\
\hline Number of region & 110 \\
\hline R-squared & 0.024 \\
\hline
\end{tabular}

As can be seen from the above chart:

(1) The test results accepted single threshold regression and the threshold value was 0.0980 .

(2) On the left side of the threshold, when the asset-liability ratio is less than 0.098,it's very significant; On the right side of the threshold, when the asset-liability ratio is greater than 0.098 , there is no significant influence.

\section{Conclusions and Recommendations}

Through regression analysis, this article draws the following conclusion: the asset-liability ratio of an enterprise value is significantly positive relationship with the enterprise value, and there is a threshold value of asset-liability ratio. Therefore, to some extent, improving the asset-liability ratio of an enterprise is conducive to improving the enterprise value, which is consistent with assumptions. From the threshold regression results, it is significant for an enterprise to improve its enterprise value by improving its asset-liability ratio, but there is a limit to the improvement of asset-liability ratio. Increasing the asset-liability ratio within the range of 0.098 can enhance the enterprise value, which is of little significance beyond this limit

According to the conclusions of this research, the following recommendations are came up with :

(1) in order to enhance the value of enterprises, enterprises can improve their asset-liability ratio to some extent and enhance their vitality to acquire greater benefits.

(2) there is a limit to the improvement of debt ratio of $S$ enterprises through the threshold. Therefore, it is meaningful for an enterprise to improve its asset-liability ratio to a certain extent, but it cannot be increased indefinitely, which is neither in line with national policies nor the requirements of economic interests.

\section{References}

[1] Ming Liu, Guoliang Yuan. Debt financing and sustainable development of listed companies. Finance research, 34-39,1999.

[2] Xixi Hong, Yifeng Shen. Empirical analysis of factors influencing capital structure of listed companies in China. Journal of xiamen university (philosophy and social sciences edition),114-120,2000.

[3] Changjiang Lv, Kemin Wang. Study on the interaction mechanism of capital structure, dividend distribution and management equity ratio of listed companies. Accounting research,39-48,2002.

[4] Hui Wang. Debt financing, corporate governance and market value of listed companies. Economic research,28-35,2003. 